\title{
Constructing a Moorean 'Open Question' Argument: The Real Thought Move and the Real Objective
}

\author{
Nicholas Shackel | orCiD: 0000-0002-1751-1400 \\ Department of Philosophy, Cardiff University, Cardiff, UK \\ Distinguished Research Fellow, Oxford Uehiro Centre for Practical Ethics, \\ University of Oxford, Oxford, UK \\ shackeln@cardiff.ac.uk
}

\begin{abstract}
How Moore's open question argument works, insofar as it does, remains a matter of controversy. The author's purpose here is to construct an open question argument based on a novel interpretation of how Moore's argument might work. In order to sidestep exegetical questions, he does not claim to be offering Moore's own argument. Rather, the author offers a reconstruction, making use of important elements of Moore's methodology and assumptions that could be reasonable within a Moorean viewpoint. The crucial role within the argument is played by what the author calls the real thought move. He shows that the reconstructed argument is more defensible from some standard objections than the common construction. The author finishes by drawing attention to a neglected objective that would make sense within Moore's viewpoint, showing that it fits with a major commitment of Bonjour's moderate rationalism, and showing how the package might be important for the non-naturalist today.
\end{abstract}

\section{Keywords}

Moore - open question argument - real thought move - real objective - intuitionism

\section{Introduction}

At the beginning of Principia Ethica Moore offers an argument for the simplicity and indefinability of good, an argument that has come to be known 
as the open question argument. The structure of the argument as a whole, given in $\S 13$ of the first chapter, is that of an argument by exhaustion. Moore considers three possibilities, that good is complex, meaningless or simple, and intends to establish the last by eliminating the first two. §13(1) is mainly directed at complexity and $\S 13(2)$ is directed initially, and rather obscurely, towards meaninglessness before turning to arguing that in being simple, good is not identical to what we mean by some other simple term.

Exactly how Moore's open question argument works, insofar as it does, remains a matter of controversy. On some views, although Moore may have pointed at something important, what he got right we have absorbed in other terms, and in any case, it was not really in or through the argument that he got it right (Darwall et al 1992, Darwall 2003, Horgan and Timmons 2006). I disagree. I think the argument brings into view (perhaps somewhat obscurely) something that remains important. And so does Fred Feldman, if I understand him aright. To my mind, Feldman shows that Moore's open question argument has been misrepresented in a certain respect. I shall not reiterate his points but remark only that I concur with his analysis so far as it goes.

In this paper I start by defending Moore from some of the things Feldman faults him for before turning to my main contributions. I shall suggest that the weight commonly placed on the openness of questions is not a good way of understanding how the argument works. Instead, I shall explain the crucial role played by what I call the real thought move and reject the analysis of this move in terms of open versus closed questions. I shall show how this move plays a significant role in every part of the argument, how it strengthens the argument by avoiding the obscurities of open questions, and how it makes sense of several steps made by Moore that are mysterious when understood in terms of the openness of questions. I shall then offer a reconstruction of the argument based on this suggestion, making use of important elements of Moore's methodology and making assumptions that could be reasonable within a Moorean viewpoint.

In offering the reconstruction I am not claiming to give an exegesis of what Moore really meant and so this paper is not intended as a contribution to Moorean scholarship. To the extent to which my reconstruction is indeed in line with Moore's intentions, to that extent he originates the reconstruction. Nevertheless, the scholar's question of whether these are really Moore's intentions or methodology or assumptions is not germane to the purpose of the paper.

Having given the reconstructed open question argument, I shall discuss some standard objections and their application to the reconstruction and move on to drawing attention to a neglected objective that would make sense within Moore's viewpoint. The methodology deployed in setting up the 
argument leads us further than has generally been attended to, to what I call the real objective. My suggestion is that what Moore was reaching for does not depend on the success of the argument but on drawing to our attention our acquaintance with goodness itself. We shall see that this acquaintance is of precisely the kind to which Bonjour has committed himself in his defence of rationalism for a priori justification. I shall finish by arguing that the real objective may yet be significant by showing how it is a commitment difficult for non-naturalists to avoid if they are to sustain a substantive moral realism that is distinct from non-reductive synthetic naturalism.

\section{Defence from Faults}

Feldman faults Moore for what he calls four preliminary problems: being 'oblivious to the use/mention distinction', oblivious to the distinction between a predicate and a general term of abstract reference ('... is good' vs 'goodness'), failing to 'appreciate the difference between the 'is' of identity and the 'is' of predication' and inconsistency 'in his use of linguistic terminology ... such ... as 'denote', 'mean', ...' (Feldman 2005, 24-26).

To the ear of modern philosophers, trained to appreciate the philosophical importance of such distinctions (a training which exists in large part because of the direction Moore's own work gave to philosophy), it may sound as if Moore is making these errors. Nevertheless, I think this is a mistake. The first mistake is evident if we attend to what he says about the sense of 'definition' he is concerned with and also what he says in $§ 13(2)$.

Moore makes clear in $\S 8$ that the kind of definition he is discussing is neither a stipulation nor a dictionary note of the use of a word. Rather (Moore $1903, \S 8)$, in giving a definition

we may, when we define horse, mean something much more important. We may mean that a certain object, which we all of us know, is composed in a certain manner: that it has four legs, a head, a heart, a liver, etc., etc., all of them arranged in definite relations to one another. It is in this sense that I deny good to be definable. I say that it is not composed of any parts, which we can substitute for it in our minds when we are thinking of it. We might think just as clearly and correctly about a horse, if we thought of all its parts and their arrangement instead of thinking of the whole: we could, I say, think how a horse differed from a donkey just as well, just as truly, in this way, as now we do, only not so easily; but there is nothing whatsoever which we could substitute for good; and that is what I mean, when I say that good is indefinable. 
In this sense of definition, Moore takes it that we are not speaking merely of the word or concept, but speaking of what it is that is whatever the word is about. We might call this a substantive or metaphysical definition. The point is, that what good is is what we mean by good when that meaning is considered in this sense of a definition. We would express this more fussily today in terms of goodness being what we mean by 'good'. But, as this passage makes clear, that Moore did not express it fussily does not mean he is oblivious to the aforementioned distinctions. Indeed, understanding the sense of definition he is concerned with depends precisely on appreciating those distinctions. Furthermore, he need only attend to linguistic terminology to the degree necessary for his discussion of the substantive definition of good that is his concern. Since he has told us clearly that this is his concern, I cannot agree that Moore's 'use of linguistic terminology ... is hard to fathom' (Feldman 2005, 26).

Finally, consider the following passage (Moore 1903, §13(2)):

It is very natural to make the mistake of supposing that what is universally true is of such a nature that its negation would be self-contradictory.... And thus it is very easy to conclude that what seems to be a universal ethical principle is in fact an identical proposition.

Moore's criticism of a specific error in understanding or inference depends precisely on distinguishing the 'is' of identity and the 'is' of predication. He is suggesting that we can mistake a true universal proposition for a logically necessary truth. For example, if we mistake 'pleasure is good' in this way, instead of taking the 'is' to be the copula, predicating goodness of whatever is pleasurable, we will take it to be the identity sign, taking goodness and pleasure to be one and the same property. There is a complication here, because his opponent might regard such moral principles as not merely universally true but necessarily true. Yet even so, it remains controversial whether (as we would put it today) necessary coextension of properties implies identity of properties.

\section{3} Challenging the Open Question in the Open Question Argument

The idea of an open question has long been thought to play an essential role in Moore's argument. The argument itself is given in §13 (Moore 1903, 15-17) and does not speak of an open question. Instead, the term is introduced later as a way we might cut someone short: 'This is not an open question: the very meaning of the word decides it' (Moore 1903, §14). It is understandable why that later term has been linked back, and Moore seems at least sometimes to 
have intended the openness of a question to play the role that has been attributed to it.

Standard objections have faulted the argument by denying the open question is truly open, or denying it can play the role attributed to it. Frankena (1939) suggests that the argument begs the question. Fumerton (1983) argues that the paradox of analysis undermines the inference from the question being open to the failure of an analytic relation (see more below). Similarly, recent defences, such as Strandberg (2004) and Altman (2004), also assume that the openness of a question is playing an essential role and have sought to show that the open question does, in fact, succeed in its role in the argument.

Here I challenge the view that the open question plays an essential role. I suggest that the openness of a question is dispensable and that the question being a question plays its role in the argument in another way, a way that I will explain and argue for in the next section. Consequently, I think the name by which Moore's argument is known is misleading.

I shall concede the temptation to give it a continuing role, but suggest that that role is not central. It merely adds support to a claim that is primarily otherwise supported and so need not depend on that support. I shall also show how the openness of a question cannot play a role in several places in the argument which, if it were playing an essential role, it would have to play. I shall call such failures of the openness of questions the incompetence of openness.

The view I am challenging construes that part of the argument directed against the complexity of the good $(\S 13(1))$ as, in essence, 'whether what we desire to desire is good is an open question, therefore good does not mean what we desire to desire'. So construed, we are led off into the obscure questions about what makes a question open or closed and what kind of entailments a question being open has for the nature of what is being queried.

Although there is a move in Moore's argument that it might be useful to refer to as the open question move, the move itself is not expressed as a question being open and I shall argue that what is held to follow need have nothing to do with what may or may not follow from a question being open.

The move I am thinking of is not discussed by Feldman. Feldman instead starts later, with Moore's contrast of the question of whether it is good to desire to desire $\mathrm{A}$ and whether the desire to desire $\mathrm{A}$ is one of the things we desire to desire. I agree with Feldman's analysis of how the argument then proceeds (see Feldman 2005, 32): essentially, by pointing out that these are distinct questions 
and then, given compositionality of meaning, validly inferring that 'to be good may mean to be that which we desire to desire' (Moore 1903, $\S 13(1)$ ) is false. So here what does the work is not (the much controverted issue of) what it is for a question to be open or closed and what follows from that, but the metaphysical question of the identity or distinction of questions.

The move in question is necessary both to set up the contrast just mentioned and to vindicate the methodology by which the distinction of the two questions is established. It is made when Moore says (1903, §13(1)):

if we carry the investigation further, and ask ourselves 'Is it good to desire to desire A?' it is apparent, on a little reflection, that this question is itself as intelligible, as the original question, 'Is A good?'

This, I think, is the source of the view I am challenging and of the discussions which attempt to clarify the notion of an open question with thoughts about the intelligibility of questions. But what is going on here and in the further argument need have nothing to do with it being an open question whether what we desire to desire is good. It is more simple than that, and its role is clearer when we see the basis on which Moore argues for the distinction between the questions (1903, §13(1)):

it is also apparent that the meaning of this second question cannot be correctly analysed into 'Is the desire to desire A one of the things which we desire to desire?': we have not before our minds anything so complicated as the question 'Do we desire to desire to desire to desire A?'

So, the distinction of the questions is taken to be established by bringing two token thoughts to mind and comparing them for identity or distinction of type. For that to be right requires two items of self-knowledge of mental states: that I have thoughts before my mind and that they are distinct. Moore assumes that, provided I have thoughts before my mind, two things follow. Not only is their identity or distinction evident (which could also be the case if one was meaningful and one meaningless) but we can also make valid comparative inferences about the meanings of the whole thoughts and the parts of which they are composed. He implicitly acknowledges that we can be deceived over whether we have a thought before the mind; we may merely feel like we do when entertaining a sequence of verbiage. It is to this last point that I believe the move is directed: simply to establishing that in entertaining whether what I desire to desire is good I actually have a thought in mind. That the question 
is intelligible is sufficient: whether it is open or not is irrelevant. The mere fact of intelligibility guarantees that I have a real thought in mind and am not selfdeceived in thinking I do. For these reasons let's call it the real thought move.

So, the real thought move is necessary for the inference that the evident distinction is not that between a thought and a mere appearance of a thought, but between thoughts of different meaning. It is only on that basis that compositionality then allows us to trace the difference in meaning between the thoughts to the difference in meaning of specific constituents of the thoughts.

There is a subtlety at this point in how the argument has established that good is not complex. Two things are going on here. The first is an appeal to self knowledge: that by direct comparison of the token thoughts, it is drawn to our attention that one constituent is complex and one is not, hence complexity alone does the work. But the inference to the good being simple need not depend on this additional piece of self-knowledge. It is supported by the detail of the case used for Moore's example, detail which also addresses a worry about that self-knowledge, viz. that we might instead be mistaking comparatively lesser and greater complexity for the simple versus the complex. ${ }^{1}$ Moore considers an analysis in terms of two simples (or perhaps I should say a repeated simple, namely, desire) and therefore we have a comparison of good with a putative analysis of minimal complexity. Since it is complexity alone, rather than the conceptual content, that identifies the distinction in meaning, we can infer from the example's instance of complexity to complexity in general; and since the case is one of minimal complexity, the inference from the distinction in meaning to the distinction between the simple and the complex is valid.

So once the real thought move is achieved, the argument may then validly proceed from the distinction of the thoughts being evident to the thinker. Baldwin (1990, 63) objects that this last must assume

that the structure of thoughts is transparently accessible to their thinker, and this is a Cartesian assumption which there is reason to reject. Thinkers are as fallible about the nature of their own thoughts as about their physical environment.

The objection, however, applies to an assumption about self-knowledge stronger than is needed. It should be noted that Moore $(1903,17)$ himself

1 My thanks to an anonymous referee for raising this worry. 
acknowledges the fallibility of the self-knowledge to which he is appealing when he later says:

although he may never become aware at all that it is different from other notions of which he is also aware.

Furthermore, that the real thought move is itself directed at an element of our fallibility is a proof that infallible self-knowledge is not being assumed. With the real thought move in view we see that what is assumed is neither general transparency nor infallibility, but only that, when taking appropriate care with not especially sophisticated thoughts using familiar concepts, the difference in complexity is apparent to the thinker. By contrast, for this kind of objection to succeed requires not merely that such self-knowledge is fallible but that it is never available.

At this point I wish to make the above mentioned concession. As we have seen, the appeal to intelligibility need only be making the real thought move. Of course, 'intelligibility' may also be taken in the sense that has been used in the common interpretation of the argument as dependent on the openness of questions. ${ }^{2}$ That is to say, it might be taken in the sense that is supposed to distinguish an open question being intelligible from a closed question not being intelligible.

We can now see that intelligibility doesn't have to be taken in the latter sense and the argument is stronger for doing so. Nevertheless, and this is my concession, that they are distinct questions may also be supported by whatever can be made of the openness of questions, and certainly this additional support makes the distinction claim stronger. ${ }^{3}$ But equally, the claim does not depend on that support, nor need that support be the central basis of the claim in how the argument works. This is a good thing since whatever concerns we may raise about the identity and distinction of thoughts, what that difference amounts to is simple, definite and absolute, whereas the difference between openness or closedness of questions has been found to be elusive, obscure and possibly relative. ${ }^{4}$ Consequently, to base the distinction of thought claim on the openness claim is to ask the elusive and obscure to underpin the simple

2 The earlier use of 'significance' on page 15 can also be taken in both ways, although its use there, perhaps, gives greater support to construing Moore's own argument as making essential use of the openness of questions.

3 My thanks to an anonymous referee for pointing this out.

4 Compare 'Identity is utterly simple' (Lewis 1986, 192). Found obscure despite (or even because of, if Quine 1951 is right) Moore's initial expression apparently basing it in analyticity. More on relativity in $\S 6$. 
and definite, which is hard enough, and the relative to underpin the absolute, which is prima facie impossible.

That the openness claim is not the central basis is additionally proved by what I shall now show. The real thought move also makes sense of the steps made by Moore at the end of $\S 13(1)$ and the beginning of $\S 13(2)$, which are only dubiously understood in terms of the openness of questions. ${ }^{5}$ For this reason reconstructing the argument on the basis of the real thought move makes the argument stronger than it would otherwise be.

The steps at the end of $\S_{13}(1)$ : The real thought move is underpinning the second argument given in the long final sentence of $\S_{13}(1)$. In this sentence Moore gives clear indication that he is assuming compositionality of meaning, since what is shown 'by inspection' of two whole propositions is that 'the predicate of this proposition - "good" - is positively different from the notion of "desiring to desire"' (1903, §13(1)). Here, 'by inspection', we doubt the equivalence of 'that we should desire to desire A is good' and 'that A should be good is good'. Then 'the mere fact that we understand very well what is meant by doubting [the equivalence] shews clearly that we have two different notions before our minds' (1903, §13(1)).

This argument is valid given the compositionality of meaning. Its major premiss is got once again from what is evident 'by inspection' on having the token thoughts before the mind. In so doing it relies explicitly on the real thought move establishing that we do indeed have thoughts before the mind, rather than mere appearances of thoughts, in order for inspection to establish their non-equivalence.

The openness of questions is playing no explicit role at all here, since what are being inspected are not questions. It is also possible that the real thought move contributes indirectly as well as explicitly, i.e. via the question's intelligibility, in the establishing-a-real-thought sense, supporting the realness of the corresponding non-questioning thought here. But if we try to extract indirect support from the openness of the corresponding question, we are in trouble. The openness of the question is, at least arguably, logically posterior to the doubting. I say at least arguably because, once again, this takes us into the obscurity concerning the openness of questions. This failure of the openness of questions to explain or validate this part of the argument is an incompetence of openness.

The real thought move also plays a significant role in the steps at the beginning of $\$ 13(2)$. The first time it is made is our second example of the incompetence of openness. Given the opening remarks of $\S 13$, we are expecting $\S_{13}(1)$

5 My thanks to an anonymous referee for suggesting that this point be given more prominence. 
to have ruled out complexity and $\S 13(2)$ to rule out meaninglessness. Yet the very first sentence of $\S_{13}(2)$ states that 'the same consideration is sufficient to dismiss the hypothesis that 'good' has no meaning whatsoever' (Moore $1903, \S 13(2))$. Because this is initially puzzling, Feldman $(2005,35)$ concludes that Moore:

muddies the waters first by suggesting that he is talking about theories according to which 'good' has no meaning whatsoever. Surely, he meant to say that he is talking about naturalistic theories according to which 'good' has no definition whatsoever.

This, I think, is a mistake. First, Feldman seems to think Moore is speaking of what we would now call non-reductive naturalist theories. That is unlikely, and to the issue of such theories we shall return later. Second, it is true that what Moore says in the rest of the section is not addressed to the meaninglessness option. Nevertheless, at the beginning of $\S 13$ he states quite simply that the alternative to complexity or simplicity is that good 'might have no meaning at all' (1903, §13), a remark closely echoed in the first sentence of section 13(2). If Feldman were right this echo would indeed be an example of the inconsistency of linguistic terminology for which he faults Moore. But he isn't right. Moore intends to rule out meaninglessness before turning to eliminating a final possibility not enumerated earlier: that good is identical to what we mean by some other simple term.

We can see this if we attend to what consideration is supposed to be sufficient to dismiss the hypothesis of meaninglessness. He is referring back to 'that we understand very well what is meant by doubting' the equivalence of the propositions 'that we should desire to desire A is good' and 'that A should be good is good'. Recall that what he takes this to be showing is the distinction of the predicates 'good' and 'desire to desire'. This distinction might yet be merely a matter of the first being meaningless and the second meaningful, so his conclusion that they are distinct is not on its own sufficient to show 'good' to be meaningful. It is, rather, the precise methodology of showing the distinction that proves it.

The non-identity of the two propositions is evident 'by inspection' provided we are not mistaken about whether we actually have the thoughts, and it is the real thought move that underwrites this assumption. Earlier we took it that compositionality was sufficient to get from the distinction in thought to non-identity of the meaning of good with the meaning of a complex. But to establish meaningfulness requires a further assumption. We need in addition that to have real thoughts requires their predicative constituent parts to be 
meaningful. Then, based on the success of the real thought move as applied in the doubting case, the distinction in thoughts shows 'good' to be meaningful. With this in mind, it is equally clear that the distinction in questions will suffice for dismissing the meaninglessness hypothesis. So, just as in the dismissal of complexity, the real thought move is essential to establishing the major premiss in the argument against the meaninglessness of 'good'. Indeed, without the real thought move we cannot make any sense of Moore's dismissal of meaninglessness.

The real thought move is equally essential to the final part of Moore's argument, in which he considers and dismisses the possibility that good is identical to what we mean by some other simple term (Moore 1903, 16-17):

Every one does in fact understand the question 'Is this good?' When he thinks of it, his state of mind is different from what it would be, were he asked 'Is this pleasant, or desired, or approved?'

From here we have essentially the same argument as the one addressed to complexity: the distinction in questions is evident to us provided we have the two thoughts, and given compositionality of meaning, the non-identity of the meaning of the relevant constituents follows. Once again the main premiss is established by the real thought move, which assures us that the difference in state of mind is that between distinct thoughts rather than between a thought and a mere seeming of a thought.

Now, with the real thought move in mind, we can reconstruct the argument thus:

1. 'Good' denotes something either complex, meaningless or simple.

2. Suppose good is complex, e.g. good is what we desire to desire.

3. 'When we think that $A$ is good we are thinking that $A$ is one of the things which we desire to desire' (Moore 1903, §13(1)).

4. 'if ... we ask ourselves "Is it good to desire to desire A?" ... this question is intelligible' $(1903, \S 13(1))$

5. On the supposed analysis of good, this intelligible question is identical to the question 'Is the desire to desire A one of the things which we desire to desire?' (1903, §13(1)). 
6. Since the question is intelligible, when we bring the two different question tokens before our mind each token is a real thought rather than either being meaningless.

7. Any distinction between real thoughts is a distinction in meaning rather than a distinction between the meaningful and the meaningless.

8. So, comparison of the tokens is a legitimate comparison of their meanings.

9. Making the comparison, it is evident that in entertaining the first token 'we have not before our minds anything so complicated as' $(1903, \S 13(1))$ what we have before our minds in entertaining the second token.

10. So, the tokens do not mean the same.

11. Since meaning is compositional, and since the difference between the tokens is constituted by the difference between predicating 'being good' and predicating 'being one of the things which we desire to desire' then 'one can easily convince himself by inspection that the predicate of this proposition - "good" - is positively different from the notion of "desiring to desire" which enters into its subject' (1903, §13(1)).

12. Because the difference in meaning detected is a difference in complexity, the contrast being with a case of minimal complexity, and since it was the complexity alone that exhibited the difference in meaning, 'good' does not denote something complex.

13. Furthermore, that we can understand what is meant by doubting whether what we desire to desire is always good 'shews clearly we have two different notions before out minds'(1903, §13(1)).

14. 'And the same consideration [i.e. that we are entertaining real thoughts entails that the difference in notions is a distinction in meaning rather than between the meaningful and meaningless] is sufficient to dismiss the hypothesis that "good" has no meaning whatsoever.' (1903, §13(2)).

15. So good is neither complex nor meaningless and is therefore simple.

16. It is tempting to mistake 'a universal ethical principle [for] ... an identical proposition.... for example [in the case of] "Pleasure is the good"' (1903, §13(2)) [i.e. confuse the 'is' of predication for the 'is' of identity].

17. One might thereby think that 'good' denotes a simple denoted by another word such as, for example, 'pleasant'. 
18. 'But whoever will attentively consider ... what is actually before his mind when he asks ... "Is pleasure ... after all good?" can easily satisfy himself that he is not merely wondering whether pleasure is pleasant'(1903, §13(2)).

19. And likewise, when we think of the question 'Is this good?' our 'state of mind is different from what it would be' when we think of 'Is this pleasant or desired or approved?' (1903, §13(2)).

20. In each case the intelligibility of the question shows we have a real thought in mind and so, since meaning is compositional, the distinction in thought proves distinction in meanings.

21. So 'good' denotes something simple and unanalysable that is not identical to simples denoted by terms such as 'pleasant' etc.

Note that lines 16 and 17 are not strictly speaking part of the argument, but an aside explaining why the final steps are taken.

I think it is evident that Moore could adopt this reconstruction should he choose to do so. Nevertheless, since from hereon I shall need to repeatedly distinguish the reconstruction from constructions of the open question argument that take the openness of questions to be essential to the argument, I shall call the latter type Moore's argument.

We might now wonder whether the reconstruction is any better at resisting the standard objections than Moore's argument. I am not here going to work through all available objections but offer rebuttals against two standard objections and a response to a third in a way that leads to the final section, in which I discuss whether the reconstructed argument has a continuing significance for non-naturalism.

The paradox of analysis is this: Apparently, analyses cannot be both true and informative because if true they must be trivial; and yet surely some analyses are both true and informative. ${ }^{6}$ The problem it poses is this. Suppose $X Y Z$ is a true and informative analysis of $A$. Being informative entails that whether $A$ is $X Y Z$ is an open question to the uninformed. Being true entails that $A$ does in fact mean $X Y Z$. Consequently, if there are true informative analyses, being an

6 Baldwin (1990, 209) attributes the paradox itself to Moore, but Langford (1942) is where it first appears in print. 
open question does not suffice to prove distinctness of meaning. So, the open question argument that relies on the openness of questions requires there to be no true informative analyses. Fumerton $(1983,492)$ puts the paradox forward as a diagnosis:

This explains what is wrong with Moore's open question argument. You cannot justifiably conclude that two questions do not have the same meaning because the one strikes you as significant, while the other strikes you as trivial.

As Fumerton runs it, true informative analyses are possible because there may be 'different-level meaning rule[s]' $(1983,491)$ that constitute an identity of meaning, but of which we are not aware. We can be informed by becoming conscious of, and of the relation of, the different level rules. Consequently, what is open for one person might be closed for another, and this makes the openness of a question relative rather than absolute. ${ }^{7}$

So the paradox of analysis objection is powerful against Moore's argument. It is so because it undermines the claim that when we detect an open question, the predicates involved are not related analytically. Nevertheless, the objection can be rebutted by the point that true substantive definitions are only transitorily informative. Once we have been informed, and come to understand it clearly, the analysis now seems trivial and the question no longer appears open (hence the relativity of the openness of questions).

In the case of attempted analyses of 'good', being informed of the putative analyses does not result in the question closing, and hence the objection fails. Admittedly, some naturalists will insist that it does close. Others, however, will say that it does not close for them. Yet, if it is a true analysis, they must already be in possession of the concepts, such as in terms of Fumerton's different-level meaning rules, so once they clearly understand it, it should close for them. This can be taken further of course, but for our purposes we merely note that in this apparent stand-off we have now met some of the obscurity of the openness of questions. So, this objection is not a clear defeater of Moore's argument.

Insofar as our reconstruction does not depend on the openness of questions, this objection struggles to get a grip. To apply it to our reconstruction it would have to attack our self-knowledge of the distinctness of thoughts. But of course, the objection itself assumes the very same thing assumed in the reconstruction, that the identity and distinction of thoughts is to some extent within our self-knowledge. Only in this way can we become informed by being told of the analysis. We must come to see that the thoughts that were apparently

7 Here I meet the promissory note given in $\S 4$. 
distinct are in fact identical. In Fumerton's example, we do this by seeing that different-level meaning rules amount to an identity of meaning where we previously thought there was a distinction. So the objection cannot attack the possibility of our simply knowing the thoughts to be distinct. It can only insist that a true informative analysis may bring to light that we are mistaken in thinking certain thoughts distinct. This is much weaker than the attack on Moore's argument furnished by undermining the openness of questions as a criterion of the distinctness of meaning. In reply, the analogous rebuttal can be given: that the appearance of a distinction in thought should then be transitory and pass when the putative analysis is understood, but it is not transitory. This reply is stronger to the extent that the attack itself is weaker.

Frankena, in his paper about the naturalistic fallacy, is widely thought to have shown that Moore begged the question in his open question argument.

Moore brings an invalid argument type into view in $§ 13(2)$ :

It is very natural to make the mistake of supposing that what is universally true is of such a nature that its negation would be self-contradictory: the importance which has been assigned to analytic propositions in the history of philosophy shews how easy such a mistake is. And thus it is very easy to conclude that what seems to be a universal ethical principle is in fact an identical proposition; that, if, for example, whatever is called 'good' seems to be pleasant, the proposition 'Pleasure is the good' does not assert a connection between two different notions, but involves only one, that of pleasure.

Frankena $(1939,474)$ responds:

while it is true that it is an error to construe a universal synthetic proposition as a definition, it is a petitio for the intuitionist to say that what the [naturalist] is taking for a definition is really a universal synthetic proposition.

Moore may appear to be doing this in $\S 13(2)$, but if we consider the import of his remarks in §9, especially the distinction between good, the property, and the good, the extension of the property, there is a better interpretation. There is an invalid argument type, and an easy way of falling into the fallacy, that Moore thinks naturalists deploy in arguing for their naturalism, of which he gives an instance:

1. 'whatever is ... good [is] pleasant' (and nothing else is).

2. Therefore 'Pleasure is the good'. 
The argument is valid if the conclusion is a universal proposition (characterising the extension of goodness) but not if the distinction between the good and good is ignored and it is taken as a statement of identity. So, yes, a naturalist might instead offer this conclusion not as a conclusion but as a definition of the identity of properties, in which case Moore would be begging the question, but Frankena is really missing Moore's point.

Furthermore, this discussion by Moore is not part of the open question argument itself. ${ }^{8}$ Its role is not to prove that good is distinct from any simple natural property, but only to block a fallacious argument for identifying good with a simple natural property. Only then does he turn to proving its distinction from any simple natural property. If at this point the naturalist abjures the fallacy and turns instead to stating that he defines good to be pleasure, even if we now take Moore's discussion to be begging the question against that definition, the naturalist is begging the question as well.

So Frankena is missing the point twice over and we must look elsewhere for where Moore's argument is supposed to be begging the question. The only other accusation of question begging from Frankena $(1939,473)$ is this:

it is begging the question in favour of intuitionism to say in advance that the quality goodness is indefinable and that therefore all naturalists commit the definist fallacy. One must know that goodness is indefinable before one can argue that the definist fallacy is a fallacy. ${ }^{9}$

This is true enough, so far as it goes. But it seems to construe Moore's arguments as consisting only in this:

1. Naturalists define good as a natural property.

2. Good is indefinable.

3. Therefore, naturalists are committing the naturalistic (= definist) fallacy.

But of course, Moore spends section 13 arguing for the very proposition that Frankena accuses him of assuming. Frankena doesn't address the argument

8 See my remark at the end of $\S 5$ about lines 16 and 17 of the reconstructed argument.

9 On the previous page there is also an instance of this mentioned with respect to a Mr Perry. 
of section 13 nor does he explain where the question begging occurs in it. The closest we get is the remark (Frankena 1939, 475):

The issue ... is one of inspection or intuition and concerns the awareness or discernment of qualities and relations. That is why it cannot be decided by the use of the notion of a fallacy.

Moore, however, has never said that the issue is decided by the notion of a fallacy. He is simply giving a name to a mistake he thinks naturalists commit, suggesting that its source may be the kind of fallacious argument or confusion he explained. He is not claiming thereby to have proved that it is a mistake. The proof, if it is one, is in $\S 13$.

Moore's argument, and our reconstruction, do indeed appeal to inspection and the self-knowledge involved may indeed be intuition, in Moore's sense of things known but not provable (see Moore 1903, §§37, 46, 65 and Moore 1939). In the case of Moore's argument, it is the openness of questions that is intuitive. A question being open does seem to imply that the predicates involved do not define one another, and vice versa, so perhaps they are logically equivalent. For this reason, Frankena may think that the openness of questions assumes the indefinability of good. Yet it would not amount to begging the question unless an assumption of the indefinability of good had been offered as the reason to believe the question open. That, however, is not what is going on: that the question is open is offered as an intuition rather than knowledge got by an inference. ${ }^{10}$

Certainly, something about whether the question 'Is pleasure good?' is open or not may invite thought about the definability of good, so one can see why the suspicion might arise. For example, if, when we want to analyse, explain or further support openness, we give up the intuition, then we may fall into a circularity by basing openness on indefinability. So the various obscurities of openness that invite further scrutiny may inadvertently lead us into a subtle assumption of indefinability when confronting the question of openness.

Nevertheless, the accusation from Frankena is that 'it is begging the question in favour of intuitionism to say in advance that the quality goodness is indefinable' (1939, 473), not that it is begging the question to say that the question is open. Provided the latter is offered as an intuition, not from an inference, the

\footnotetext{
10 In general, just because $P$ is logically equivalent to $Q$ does not mean giving $P$ as a reason for $Q$ is question begging: one would need also to be giving $Q$ as the reason for P. My thanks to an anonymous referee for asking about this.
} 
accusation taken in this way is not well made out. That being said, we must grant that the continuing obscurities of openness must leave this challenge to Moore's argument not fully settled.

In the case of our reconstruction, however, the matter is much clearer. Here we assume only that the distinction of thoughts can be evident in suitable circumstances, and then infer the distinction of meaning. It is only from the various distinctions in meaning that the indefinability of good is finally inferred.

The place in the reconstructed argument where inspection and intuition play a role is where various thoughts are held to be distinct. If Frankena's point was only that at this point we meet a clash of intuitions, it might be true. But that would be to give up the objection that the argument begs the question by assuming indefinability.

To maintain the objection requires showing that the intuition of distinct thoughts assumes the indefinability of good. Evidently, that would be hard to do. It isn't assumed in any straightforward sense. The intuition that they are distinct is not itself an inference but a piece of self-knowledge by acquaintance with the thoughts, a forteriori it is not an inference from the assumption that good is indefinable. Indeed, the power of the reconstructed argument is that it requires no thoughts about definability. I need have had no prior thought on whether good was definable or indefinable, indeed, I might never have thought about the question before. Nor need I make use of any thoughts about its definability in following the argument. The argument draws my attention to token thoughts and to whether they are distinct, and on reflection I find them so (or not). It is especially clear in the earlier part of the argument (lines 9, 13 and 14 in the reconstruction) that no assumption about indefinability could play a role, since the distinctness is to be judged not on the ground of the meanings but on the ground of their form. It is not quite so straightforward in the later part of the argument (lines 18 and 19) since the difference in form doesn't play the same role, but the intuition is still a matter of acquaintance with the thoughts and their distinctness rather than involving thoughts about indefinability. So even if Frankena's question begging objection poses some difficulty for Moore's argument, it does not do so for the reconstruction.

We now turn to the objection given by Cornell realists (Railton 1986, Boyd 1988, Brink 2001, Sturgeon 2003). Moore assumes that the distinction of meaning entails a distinction between properties. If, however, Frege's distinction between sense and reference is correct, that assumption is false since the distinction might be in sense rather than in reference. So, a naturalist might claim that the identity of good with some natural property is synthetic rather than analytic. 
There is, of course, a much wider discussion to be had about whether this syntheticity move is legitimate. It is plainly legitimate for the concept water, which is a natural kind concept, but the concept of goodness might yet be one for which distinction of meaning does entail a distinction between properties. So when the argument is over whether good is a natural kind concept, the assumption that there is a synthetic move to make is potentially question begging, absent some further independent argument. Here, however, is not the place to pursue that line of thought.

A further issue is whether the claimed synthetic identity is reductive or nonreductive. Cornell realists have sometimes been unclear which kind they are offering. For example, Boyd $(1988: \$ 2.5)$ claims to deal with the challenge from the open question argument, which he articulates as

if goodness would be a natural property, then isn't moral realism committed to the extremely implausible claim that moral terms like 'good' possess naturalistic definitions?

His answer to this is that his example of synthetic naturalism, which he calls homeostatic consequentialism, is non-reductive (Boyd 1988:§4.5):

we have seen that a moral realists rebuttal to these challenges is possible which assimilates moral terms to naturalistically and non-reductively definable terms.

On the other hand, his homeostatic consequentialism looks as if it likens good to a complex natural property, similar to the way health may be a complex, which could be understood as asserting a reduction of good to that complex.

Railton, who is unquestionably a reductivist, explicitly states that his reduction amounts to a reformed definition of morality in terms of a complex natural property. The non-naturalist has a different kind of defence here, namely, the objection to changing the subject.

I am not here attempting to rebut all threats from synthetic naturalism. The strongest threat comes from non-reductive synthetic naturalism. The reason for this is that the open question argument (if successful) rules out reductive synthetic naturalism because the reduction is to a complex natural property and the open question argument rules out complexity. Whereas, as Brink, Boyd and Sturgeon point out, the non-reductive synthetic naturalist can accept the open question argument for indefinability and challenge the inference from simple to non-natural. 
The difference between non-naturalism and non-reductive naturalism can now become difficult for the non-naturalist to sustain, since both agree that goodness is simple and unanalysable and both agree that it supervenes on natural properties. Sturgeon attempts to show that goodness (moral properties, in his actual arguments, but I'll stick to goodness for simplicity) has causal powers and is therefore natural.

Rather than rebut this objection here, I am going to grant the point so far as it goes, i.e. that our reconstruction does not rule out non-reductive synthetic naturalism. In the next section I show why a further move made by Moore would do so, if right.

\section{7 \\ Moore's Coda and the Real Objective}

I have shown that Moore's Section 13 contains three arguments, one against complexity, one against meaninglessness and one against identifying good with some other simple property. The arguments, at least as reconstructed, are essentially the same and the crucial premiss in each is the non-identity of a pair of questions or propositions. The crucial premisses are not argued for. Rather, the real thought move is providing us with the materials for realizing the non-identity from our knowledge of the identity and non-identity of our own mental states. We are not assuming complete transparency since the point of the real thought move is to assure us that a certain error we can be led into by entertaining a sequence of verbiage is not occurring in this case.

I think it is important that Moore did not stop here. In the concluding remarks of Section 13, which I shall call the coda, Moore makes an extraordinary move (a move that Feldman does not attend to at all). Moore says (1903, §13(2), my emphasis):

if he will try this experiment ... he may become expert enough to recognise that in every case he has before his mind a unique object, with regard to the connection of which with any other object, a distinct question may be asked. It has a distinct meaning for him, even though he may not recognise in what respect it is distinct. Whenever he thinks of 'intrinsic value,' or 'intrinsic worth,' or says that a thing 'ought to exist,' he has before his mind the unique object - the unique property of things - that I mean by 'good.' Everybody is constantly aware of this notion, although he may never become aware at all that it is different from other notions of which he is also aware. But, for correct ethical reasoning, it is extremely 
important that he should become aware of this fact; and as soon as the nature of the problem is closely understood, there should be little difficulty in advancing so far in analysis.

What he has said here (at least, as I propose to reconstruct it) is that by thinking of intrinsic value, etc., we are acquainted in our thought with the simple property of goodness. Furthermore, attending to the way he presents this, this is the objective that he is really after. But it is not argued for. It is rather that the process of following his reasoning has given us the material by which, if we will try his experiment and note the correctness of the real thought move in each case, we may now realise this acquaintance ourselves.

Bringing to our attention our already existing acquaintance with goodness is what I shall call Moore's real objective. With this Cartesian methodology, we transcend the open question argument and learn that intuitionism about morality is possible because of our acquaintance with goodness. I shall call this acquaintance with goodness and other moral properties Moorean intuitionism.

That this is what is going on is clearer if we recall Moore's view of semantics. Here I follow Baldwin's analysis in Chapter 2 of his book on Moore's philosophy. Baldwin shows that Moore has a 'one-level conception of meaning' (Baldwin 1990, 45)." Although Moore changed the philosophical ground for this view between 1899 and 1901 (Baldwin 1990, 45-47), the one-level view itself remained the same. Moore rejects Frege's distinction between sense and reference (Frege 1948). There is no sense, no mode of presentation, to be what is the 'distinct meaning' that is 'before his mind' when he thinks of 'intrinsic value'. There is only the referent itself, 'the unique property of things that I mean by "good"'. Under this view, the meaning of 'good' can only be goodness itself and so to have that meaning before our mind is to have goodness itself before our mind, and to do so with an acquaintance sufficient to know its nature is distinct from that of pleasure..$^{2}$

It is both striking and important that we find a contemporary philosopher committed to exactly this acquaintance with properties. In his Defence of Pure Reason Bonjour gives his case for a moderate rationalism for a priori justification. One example he uses of an a priori justified belief is that 'nothing can be red all over and green all over at the same time' $(1998,100)$. In Chapter 6 he

11 My thanks to an anonymous referee for pointing out the value of using of Baldwin's analysis at this point.

12 Although Moore's path here depends on denying Fregean senses, the acquaintance itself is evidently consistent with distinguishing properties from concepts of properties. 
considers metaphysical objections to rationalism and in $\S 6.3$, 'The Nature of Thought', he develops this entailment of his rationalism (Bonjour 1998, 162, my emphasis):

A person apprehends or grasps, for example, the properties redness and greenness, and supposedly "sees" on the basis of this apprehension that they cannot be jointly instantiated. Such a picture clearly seems to presuppose that as a result of this apprehension or grasping, the properties of redness and greenness are themselves before the mind in a way that allows their natures and mutual incompatibility to be apparent.

In his replies to a symposium on his book he strengthens this (Bonjour 2001, 677):

it becomes clear at once that at least many ... a priori insights are ... of this non-propositional sort. Consider the one involved in the color incompatibility case. What is most fundamentally grasped or apprehended there, I would now suggest, is the actual relation of incompatibility between the two colors, the way in which the presence of one excludes the presence of the other, with the propositional awareness that this is so, that nothing can be red and green all over at the same time, being ... secondary and derivative.

This is exactly the acquaintance that Moore is drawing to our attention, only in Moore's case he is setting it up in order to bring the properties of goodness and pleasure before our mind in a way that allows their natures and distinctness to be apparent.

The suggestion I want to argue for here is that, understood in this way, Moore may well be doing what a non-naturalist must do. Furthermore, part of the reason that it might be what must be done is to do with the problem of distinguishing non-naturalism from non-reductive synthetic naturalism whilst justifying a substantive realism for moral properties.

Non-reductive naturalism can explain how we have moral knowledge in the same way any natural knowledge can be explained and the moral properties of which we have knowledge have thereby the same substantive reality as any natural property. Consequently, non-reductive naturalism justifies the reality of moral properties just as naturalism in general justifies the reality of any natural properties, and hence has no difficulties, or no special difficulties, in justifying a substantive moral realism.

Non-naturalists say moral knowledge is based in reason and that we know the fundamental moral principles by the exercise of our rational intuition. 
The difficulty here is to explain just how that amounts to access to substantively real moral properties. Moorean intuitionism explains it by saying that we are acquainted with them and can know of that acquaintance when we attend to our thoughts about them in the right way. To simplify matters a little, embarrassment at Moorean intuitionism has led non-naturalists to appeal instead to the self evidence of fundamental moral principles (e.g. Audi 1997, Ch.2 and Shafer-Landau 2003, Ch.11) or to quietism (Parfit 2011, Ch.31 and Scanlon 2014). There is not space enough to go into depth here, but I am now going to sketch how Moorean intuitionism may yet stand better than these current approaches.

A problem with a defence of the non-natural reality of morality on the basis of moral knowledge got from self-evidence is that it does not achieve enough. ${ }^{13}$ We can fabricate a collection of moral concepts arranged prettily, the principles of which arrangements will thereby be self-evident, but morality itself might then be nothing but a castle built in the air. Self-evidence cannot demonstrate more than this for the nature of morality and consequently our moral knowledge might be nothing more than our knowledge of a fiction. So this account of moral knowledge does not suffice to address the threat of fictionalism. And there are further threats. If the fabrication is instead the manifestation or constitution of some kind of practical agreement then we have constructivism. Perhaps the best that can be made of it is a kind of mind-dependent conceptualism for moral properties. But in all such cases, we do not have a substantive moral realism.

The other modern approach to establishing the non-natural reality of moral properties is to be found in quietism, which is developed by Parfit $(2011,479)$ in his Non-Metaphysical Cognitivism:

$(F)$ There are some claims that are, in the strongest sense, true, but these truths have no positive ontological implications.

13 For clarity, the self-evidence in question here is supposed to suffice for moral knowledge without the kind of acquaintance with moral properties we have been discussing. Rather, the putative self-evidence of a moral proposition requires only a possession of the moral concepts sufficient for understanding it, and understanding the proposition on that basis alone makes it evident. One might call a moral proposition known by Moorean intuition self-evident, but it would be self-evident in a different way, namely, because the acquaintance with the moral properties makes their nature and relations evident. Bonjour appears to use 'self-evident' in the former way (1998 §4.2), but later (as we saw above 1998 §6.3) he makes it clear that what he means by understanding a proposition requires, at least sometimes, self-evidence in the latter Moorean way. 
$(G)$ When such claims assert that there are certain things, or that these things exist, these claims do not imply that these things exist in some ontological sense.

On this view, moral properties exist (because it is a moral truth that goodness exists), but not in an ontological sense of existing. This is self-contradictory: to exist is to be and the ontological sense of existence is being, so goodness has being and does not have being, or more simply, goodness is and is not. The contradiction can be avoided if existing only in the non-ontological sense of existing amounts to fictional existence, but I assume that he intends 'the strongest sense' of truth to rule that out. I think Parfit is right that this is where quietism must end up, but to end up here is to exhibit its failure.

So, the non-naturalist must somehow show that those concepts are concepts of real properties without ending up in a position indistinguishable from non-reductive synthetic naturalism. The base properties of morality, such as good and bad, right and wrong, are simple. If a simple property is not a property of which we may gain knowledge through its role in a theory (as we may for natural properties), then all that can be done, after perhaps some needed ground clearing, is to draw our attention to our acquaintance with the property. And that is exactly how we should reconstruct what Moore is aiming to do. Non-naturalists must take it that we can be acquainted with moral properties and that as a result our moral concepts are self-revelatory, in the sense of being concepts whose possession allows, and is perhaps grounded in, acquaintance with the properties that are their meanings.

We can now see why Moore is not much concerned with the issues for which Feldman faults him. A substantive definition of good is a definition of what good is. On this reconstruction, Moore thinks that we are already perfectly aware of what good is, ${ }^{14}$ because we are acquainted with it and the clarity in that acquaintance will show it to be the metaphysical simple that it is. In showing that 'good' is not synonymous with anything else, there is no distinction to be made between its meaning and the 'unique property of things' that goodness is. Admittedly, by immediately speaking of the property as a notion he is failing clearly to distinguish the meaning of the concept from the concept whose non-synonymy has been his subject. Nevertheless, he clearly thinks concept and meaning are intimately united in our thoughts. And this is why proper reflection on our thoughts will not only ground the main premisses for the argument but also, for those who will try his experiment, reveal our acquaintance with goodness itself.

14 Hence his remark mentioned above (when outlining substantive definition) that 'we may mean that a certain object, which we all of us know ...' (Moore 1903, §8). 
My final suggestion is that Moore, at least as reconstructed here, may be quite right in having this as the real objective of his demonstration. Modern non-naturalists, embarrassed by the real objective, have sought to provide for the substantive reality of moral properties in other ways. As we have seen, prima facie those ways do not distinguish non-naturalism from fictionalism and lack any obvious additional resources to vindicate the non-natural reality of moral properties. So, if non-naturalism is to maintain its distinction from a non-reductive synthetic naturalism whilst retaining the possibility of moral knowledge of a substantive moral reality, then the coda articulates an important and possibly unavoidable commitment of non-naturalism, namely, what I have called Moorean intuitionism.

Moore was, therefore, more clear-sighted than modern non-naturalists. Reconstructing Moore's coda shows Moorean intuitionism to be the real objective, an objective that is, as we have seen, very much needed by the nonnaturalist. Furthermore, having attained that objective, we can look back at the reconstructed open question argument and see it to be strengthened. All along, when real thoughts were brought to our attention, we were also being reacquainted with goodness itself, and consequently our judgements of distinctness, which gave us its premisses, were more strongly grounded than we had realized before. For all these reasons, then, the open question argument and its coda as reconstructed herein should continue to occupy our attention. That being said, whether Moorean intuitionism is a congenial position for nonnaturalism to end up in, I leave to others to determine: it might be as much a reductio of non-naturalism as the only possible vindication.

\section{References}

Altman, Andrew 2004. "Breathing Life into a Dead Argument: G. E. Moore and the Open Question." Philosophical Studies 117 (3), 395-408.

Audi, Robert 1997. Moral Knowledge and Ethical Character. New York: Oxford University Press.

Baldwin, Thomas 199o. G. E. Moore. London: Routledge.

Bonjour, Laurence 1998. In Defense of Pure Reason: A Rationalist Account of a Priori Justification. Cambridge: Cambridge University Press.

Bonjour, Laurence 2001. "Replies." Philosophy and Phenomenological Research 63 (3), 673-698.

Boyd, Richard Newell 1988. "How to Be a Moral Realist." In Essays on Moral Realism, edited by Geoffrey Sayre-McCord, Ithaca: Cornell University Press, 181-228.

Brink, David Owen 20o1. "Realism, Naturalism, and Moral Semantics." Social Philosophy and Policy 18 (2), 154. 
Darwall, Stephen 2003. “Moore, Normativity, and Intrinsic Value." Ethics 113 (3), 468-489.

Darwall, Stephen, Gibbard, Allan \& Railton, Peter Albert 1992. "Toward Fin De Siècle Ethics: Some Trends." Philosophical Review 101 (1), 115-189.

Feldman, Fred 2005. "The Open Question Argument: What It Isn't; and What It Is." Philosophical Issues 15, 22-43.

Frankena, William Klass 1939. "The Naturalistic Fallacy." Mind 48 (192), 464-477.

Frege, Gottlob 1948. "Sense and Reference." The Philosophical Review 57 (3), 209-230.

Fumerton, Richard Anthony 1983. "The Paradox of Analysis." Philosophy and Phenomenological Research 43 (4), 477-497.

Horgan, Terry \& Timmons, Mark 2006. "Metaethics after Moore." In Metaethics after Moore, edited by Terry Horgan and Mark Timmons, Oxford: Clarendon Press, 1-17.

Langford, Cooper Harold 1942. "Moore's Notion of Analysis." In The Philosophy of G. E. Moore, edited by Paul Arthur Schilpp, Chicago: North Western, 319-343.

Lewis, David 1986. On the Plurality of Worlds. Oxford: Blackwell.

Moore, George Edward 1903. Principia Ethica. Cambridge: Cambridge University Press.

Moore, George Edward 1939. "Proof of an External World." Proceedings of the British Academy 25 (5), 273-300.

Parfit, Derek 2011. On What Matters. Oxford: Oxford University Press.

Quine, Willard van Orman 1951. “Two Dogmas of Empiricism.” The Philosophical Review $60,20-43$.

Railton, Peter Albert 1986. "Moral Realism." The Philosophical Review 95, 163-207.

Scanlon, Thomas 2014. Being Realistic About Reasons. Oxford: Oxford University Press.

Shafer-Landau, Russ 2003. Moral Realism a Defence. Oxford: Oxford University Press.

Strandberg, Caj 2004. "In Defence of the Open Question Argument." The Journal of Ethics 8 (2), 179-196.

Sturgeon, Nicholas L. 2003. “Moore on Ethical Naturalism.” Ethics 113 (3), 528-556. 